\title{
Comparative Study on Mass Sporting Activities in Northern Shaanxi
}

\author{
Chunlan Li \\ College of Education and Public Management, Weinan Normal University, Weinan, Shaanxi (714099)
}

\begin{abstract}
By applying the methods of field investigation, expert interviews, literature data, etc., the paper conducts a research on the status quo of mass sporting activities of Northern Shaanxi (Yan'an and Yulin). It is learned that, there is a huge difference among different areas of northern Shaanxi in mass sporting activity development, with Yan'an better than Yulin. The common problems include few activity sites, few activities, lack of sports instructors, and insufficient sports venues and facilities. It is suggested that, government makes good use of local resources, invests more on public sport venues and mass sporting activities and increases public awareness on physical exercise; social sports instructors carry out their responsibility and duty to promote mass sporting activities; school and enterprises open more venues to the public.
\end{abstract}

KEYWORD: Southern Shaanxi; organize; carry out; status quo

\section{INTRODUCTION}

In order to guarantee the legitimate rights and interests of citizens to participate in the sporting activities, promote the nationwide fitness programs, improve the healthy quality of citizens, and increase the social harmony, the $33^{\text {rd }}$ meeting of the $10^{\text {th }}$ Standing Committees of the People's Congresses of Shaanxi province passed the "Shaanxi Provincial Mass sporting Regulations" (hereinafter referred to as the "Regulation") on September $27^{\text {th }} 2007$ in accordance with the "Sports Low of the People's Republic of China", related laws regulations of Shaanxi province, and according to the real conditions of Shaanxi province. The "Regulation" took effect in December $1^{\text {st }} 2007$. In order to fully understand the mass sporting activities in the province after the implementation of the "Regulation", the research team of the "Study on the Current Condition of Mass Sporting Path Project of Shaanxi Province and its Development Strategy", conducted a series of researches on the mass sporting activities of Guanzhong Region of Shaanxi province. Based on the related data of Sports Bureau of Shaanxi province, and by processing and analyzing the investigation results, the research team has made an objective conclusion and proposed feasible suggestions. The study also provides reliable theoretical basis for related government agencies to optimize policies, and improve the effect of mass sporting activities, so as to promote the faster and better development of mass sporting activities in Shaanxi province.

\section{RESEARCH OBJECTS AND METHODS}

The study objects of this paper are urban and rural residents of Northern Shaanxi, namely, Yan'an and Yulin. The research methods used in this study include field investigation, random interviews, literature data, and mathematical statistics. The research and analysis on the aspects of population, mass sporting activities, social sports instructors, sporting facilities, and investment on mass sporting activities of three cities of Northern Shaanxi has been made.

\section{INVESTIGATION RESULTS AND ANALYSIS}

Yan'an has long been the political, economic, cultural and military center of Northern Shaanxi and the sacred place of Chinese revolution. It has a total

Funded Program: the program of Education Bureau of Shaanxi Province (2013JK0517)

Author: Li Chunlan (1975-), Female, Native of Hua County, Shaanxi Province, Master Degree, Associate Professor, College of Education and Public Management, Weinan Normal University, Research Interests: Sport Sociology 
area of $36,712 \mathrm{~km}^{2}$ and a population of $2,194,000$. Yulin, located in the northern part of Shaanxi province, is the junction of Shaanxi, Gansu, Ningxia, Inner Mongolia and Shanxi province with a total area of $43,578 \mathrm{~km}^{2}$ and a population of 3,352,400.

\subsection{Mass sporting activities organized in the cities of Northern Shaanxi (2011)}

\subsubsection{The Number of activities and participants}

Table1 The number and the participants of mass sporting activities organized in the cities

\begin{tabular}{|l|l|l|}
\hline & Yan'an & Yulin \\
\hline Number of activities (times) & 20 & 22 \\
\hline Number of participants(10,000) & 25 & 11 \\
\hline
\end{tabular}

Combining Table 1 with the cities' populations, it is clear to see that Yan'an held 20 activities in 2011 with 250,000 participants, having relatively higher participation level of 12,500 participants per activity on average. And Yulin held 22 activities with 110,000 participants, having a participation rate of $50 \%$, much lower than that of Yan'an. Therefore, it can be concluded that mass sporting activities are more influential and fruitful in Yan'an.

\subsubsection{Existing Sports Sites}

Table 2 Existing Sports Sites in the Cities

\begin{tabular}{|l|l|l|}
\hline & Yan'an & Yulin \\
\hline Newly added sites & 7 & 18 \\
\hline Accumulative total at the end of the year & 134 & 158 \\
\hline
\end{tabular}

The number of sports sites, there are 134 activity sites in Yan'an City, and there is one activity site available for each 16,400 people. There are 158 activity sites in Yulin City, and each site available for every 21,200 people. From table 1 it can be seen that, a total number of 12,500 people participate in the activities every time, and there is one activity site available for each 16,400 people. If these activity sites could evenly distributed in the city, the target for enhancing the awareness in physical exercises, and for notable increase of number of participants of mass sporting activities in Yan'an City will be realized.

\subsection{Social sports instructors in cities of Northern Shaanxi}

Table 3 Number of social sports instructors in the cities

\begin{tabular}{|l|l|l|}
\hline & Yan'an & Yulin \\
\hline National second level & 309 & 120 \\
\hline Accumulative total at the end of the year & 991 & 400 \\
\hline National third level & 133 & 250 \\
\hline Accumulative total at the end of the year & 443 & 600 \\
\hline
\end{tabular}

It can be seen from Table 3 that in Yan'an both the growth rate and the total number of level-3 social sports instructor are greater than those of level-2 instructors. However, the situation is opposite in Yulin, from which we can find that the development model of Yan'an is backbone-led improvement while Yulin's model is general improvement. In recent years, the social sports instructor team of China has been constantly growing, and so far it has exceeded 0.7 million. This figure is expected to reach 1 million in 2015, and the target of Shaanxi is to have one social sports instructor for each 1,000 people. So far, there is one social sports instructor available for each 1,529 people in Yan'an city, and only one for each 3,352 people in Yulin, so it has long way to go to reach the target. Therefore, it requires Yulin to strengthen the training on social sports instructors, so as to provide better services for mass sporting activities. In the study, the author conducted random interviews with some population groups. The interview result shows that, many participants neither know how to choose suitable sports programs for them, and nor how to take exercise. Most of them just simulate others but they don't know what does "aerobic exercise" and "anaerobic exercise" mean. Lack of sports instruction and insufficient sports knowledge directly restricts the development of mass sporting activities of northern Shaanxi.

\subsection{Investment on mass sporting activities of cities of Northern Shaanxi}

Table 4 Investment of cities on mass sporting activities (10,000Yuan)

\begin{tabular}{|l|l|l|}
\hline & Yan'an & Yulin \\
\hline Fiscal expenditure & 163 & 500 \\
\hline Public welfare fund from lottery & 300 & 1000 \\
\hline Social investment & 5 & 150 \\
\hline
\end{tabular}

The "National Health Regulations" requires to incorporate the mass sporting cause into the related regional economic and social development plans, and to list the expenses of mass sporting work into local financial budget. The public welfare fund from lottery arranged by administrative departments of sports is mainly used for mass sporting cause. It can be seen from the table 4, In 2011, the total investment on mass sporting cause was 4.68 million Yuan in Hanzhong, with 2.133 Yuan per capita, total investment on mass sporting cause in Ankang was 16.50 million Yuan, with 4.921 Yuan per capita, which were higher than other cities in Shaanxi, but were still much lower than the per capita investment of 8 Yuan required by General Administration of Sport of China. 


\subsection{Sports venues for mass sporting activities of cities of Northern Shaanxi}

It is found from researches that Yan'an has increased its investment on sport venues and facilities, strongly encouraging the sports and fitness projects in township. Yulin has also put forward sports projects so as to better develop mass sporting activities, to increase public awareness on sports participation, and to implement people-benefit projects on mass sporting activities. The majorities of these sports venues neither belong to "society" nor to "communities" but belong to "departments" and "schools". Some of these sports venues charge fees for use, and rest of them are not open to the public. Only very few sports venues are available for mass sporting activities. Despite the orderly construction of the mass fitness paths, we find the situation less satisfactory: much attention is paid to construction but less to management and many sports facilities are unsupervised, damaged and missing. The reason is that after installation of sports facilities, related departments neither signed the using and management agreement with the receiving units, nor tracked or inspected service conditions of those sports facilities. Receiving units did not assign designated persons to maintain and manage the facilities. Damaged facilities were neither maintained and repaired, nor were placed. Some of facilities were even lost.

\section{CONCLUSION AND SUGGESTIONS}

There is a huge discrepancy between Yan'an and Yulin, two cities in the Northern Shaanxi area, in terms of mass sporting activities. The former has smaller population but has held more activities with more participants in more sites. By contrast, mass sporting activities in Yulin are less influential and fruitful. It is suggested that sports administrative departments of the above cities should earnestly implement the document of Shaanxi province, and fulfil their duty to organize mass sporting activities. It is also suggested that sports administrative department should strengthen the promotion of mass sporting activities, to enhance the exercise consciousness of the public in the forms of propagandist manual, exercise handbook, audiovisual materials, and lectures, to increase the number of mass sporting activities and focus on the effect of activities, try to increase its participant number by adding more activity sites.

Lack of sports instructors and insufficient sports knowledge directly restricts the mass sporting activities of Northern Shaanxi. Compared with the steady growth of social sports instructors' number in the whole Northern Shaanxi area, Yulin's growth rate is rather slow, which to some extent will affect its development of mass sporting activities. It is also suggested that social sports instructors should organize regular education programs for residents of communities, to allow them to understand the aims and significance of physical fitness, and understand the importance of scientific fitness, as well as to allow them to master one or two basic sports methods and to be able to conduct simple self medical supervision. Meanwhile, sports administrative departments should strengthen the training, management, and appraisal on the social sports instructors, to encourage them to fulfil their duties of disseminating the knowledge of sporting activities, imparting sporting exercise skills, and teaching the sporting exercise method, and to organize related sports activities.

Insufficient investment and lack of sports venues and facilities are the major reasons that directly affect the sustained and effective development of mass sporting activities in Northern Shaanxi. With its abundant mineral resources, governments and sports administrative departments of Northern Shaanxi area shall mobilize all available social resources, broaden financing channels, increase the investment on mass sporting cause, build more sports venues, install more suitable sports facilities according to their real conditions, open more sports venues of schools and organizations to the public, and share all available resources, so as to provide maximum guarantee for the better development of mass sporting activities.

\section{REFERENCES}

[1] Shaanxi Provincial Bureau of Statistics. Shaanxi Province Statistical Yearbook 2012. Beijing: China Statistical Publishing House, 2013.

[2] Wu Changling, Zhu Yuanli. Instruction of Mass Sporting Activities. Shaanxi: Shaanxi Science \& Technology Press, 2011.

[3] Editing Team. Current Development and Future of Sports Science. Beijing: Beijing Sport University Press, 2002.

[4] China's Mass Sports Survey Team. Investigation and Research on the Status Quo of China's Mass Sports. Beijing: Beijing Sport University Press, 2005.

[5] General Administration of Sport Plans to Increase the Investment in Mass Sporting [EB/OL]. http://bjyouth.ynet.com/3.1/1105/25/5982663.html, May $25^{\text {th }} 2011$.

[6] Standards for Evaluating the Implementation of the National Fitness Program (2011-2015) [EB/OL]. http://www.sport.gov.cn/n16/n33193/n33208/n33418/n33 598/n2030657.files/n2030668.doc, Oct. 2012. 